\title{
General Psychiatry Olanzapine-induced leucopaenia and thrombocytopaenia in an elderly patient: a case report and review of the evidence
}

\author{
Yogender Kumar Malik, Swapnajeet Sahoo, Ajit Avasthi
}

To cite: Malik YK, Sahoo S, Avasthi A. Olanzapineinduced leucopaenia and thrombocytopaenia in an elderly patient: a case report and review of the evidence. General Psychiatry 2018;0:e000013. doi:10.1136/ gpsych-2018-000013

Received 09 January 2018 Revised 26 June 2018 Accepted 06 July 2018
Check for updates

(c) Author(s) (or their employer(s)) 2018 . Re-use permitted under CC BY-NC. No commercial re-use. See rights and permissions. Published by BMJ.

Department of Psychiatry, Post Graduate Institute of Medical Education and Research, Chandigarh, India

Correspondence to Swapnajeet Sahoo; swapnajit.same@gmail.com

\section{SUMMARY}

Haematological adverse effects of antipsychotics are rare but life threatening. Existing literature is limited to case reports, which are mostly reported on second generation antipsychotics (clozapine, olanzapine, risperidone, quetiapine). Elderly individuals are at risk of developing side effects with any psychotropics. Olanzapine is commonly used for the management of psychotic symptoms as well as for the management of behavioural and psychological problems with dementia in the elderly. In this case report, we report thrombocytopaenia and leucopaenia in an elderly individual with schizophrenia which developed after initiation of olanzapine and reverted back after stoppage of the drug. This case report highlights that the elderly are susceptible to develop haematological side effects with olanzapine and hence monitoring may be essential.

\section{INTRODUCTION}

Blood dyscrasias (leucopaenia-total leucocyte count $<3500 /$ cumm, thrombocytopaenia-total platelet count $<150 \quad 000 /$ cumm, pancytopaenia) are rare but life-threatening adverse effects with antipsychotics, mostly reported with second generation antipsychotics. Available literature suggests that antipsychotic induced haematological adverse effects are mostly idiosyncratic. Most of the literature on haematological adverse effects (mostly leucopaenia, neutropaenia and thrombocytopaenia) has been well documented with regard to clozapine. ${ }^{1-3}$ However, there is also evidence (though limited) for the haematological adverse effects of other second generation antipsychotics like risperidone $\left(\right.$ oral $^{4-7}$ ) as well as in depot long acting preparations, ${ }^{8}$ quetiapine ${ }^{9-12}$ and olanzapine. ${ }^{13-22}$ With regard to olanzapine, while some have reported the haematological abnormalities to be reversible, ${ }^{1823} 24$ others have reported them to be fatal. ${ }^{1525}$ A recent systematic review on the available literature of the haematological side effects of olanzapine from 1998 to 2015 revealed a total of
38 publications (in the age range of 16-83 years).$^{26}$ Of all these case reports, to date only seven case reports on the haematological adverse effects of olanzapine have been reported in elderly patients ${ }^{1314182327-29}$ and others have been reported in adolescents, youth and middle-aged subjects. ${ }^{26}$

Though no particular risk factors have been evaluated in this regard, it is a well-known fact that extremes of age (children and elderly, ie, $>55-60$ years of age) is a risk factor for developing any adverse effect with any psychotropics. In view of this limited literature on the association of olanzapine and blood dyscrasias in the elderly, we report a case of a 62-year-old man with paranoid schizophrenia who developed leucopaenia and thrombocytopaenia while on olanzapine.

\section{CASE DESCRIPTION}

Mr G, a 62-year-old married man, retired electrician by occupation was brought by his family members with complaints of hearing of voices over the past 10 years. There was no relevant medical history or family history of mental illness. Detailed exploration of history revealed an illness of insidious onset with a continuous and progressive course which was precipitated by interpersonal problems with office colleagues. Following which initially, the patient started to harbour strong fixed false beliefs that his colleagues wanted to defame him with subsequent anger-outbursts, agitation and suspiciousness towards them. Later on, after few months, he even started to hear voices of his office colleagues in clear consciousness discussing him and commenting on his actions using derogatory language. Due to these events, there was significant socio-occupational dysfunction. He was treated with risperidone (2-4 $\mathrm{mg}$ /day) with good compliance for a period 
of 6 months with which there was about $60 \%$ improvement but later because of non-compliance and restarting of risperidone he did not show any response. Detailed general physical and systemic examination did not reveal any abnormality and mental status examination was suggestive of auditory hallucinations-third person discussing type, delusions of persecution and reference, low mood and suicidal ideations secondary to psychotic symptoms with absence of insight and intact cognitive functions (Mini mental state examination-28/30). A diagnosis of paranoid schizophrenia as per ICD-10 was considered. After all essential routine haematological (complete blood count) and biochemical investigations (serum electrolytes, liver function tests, lipid profile, renal function tests, serum vitamin B12 and folate), all of which came out to be normal, he was started with Olanzapine $5 \mathrm{mg}$ which was gradually increased to $15 \mathrm{mg}$ over a period of 3 weeks ( $5 \mathrm{mg}$ increment in dose per week). There was reduction in psychotic symptoms by $40 \%-50 \%$ but on subsequent follow-ups, after 6 weeks of starting Olanzapine, the patient complained of excessive fatigability. On repeat investigations, there was evidence of total leucocyte count of 2600/cumm (baseline-9400/ cumm) and total platelet count of $45000 /$ cumm (baseline-130 000/cumm) without any evidence/history of fever and symptoms suggestive of any local or systemic infection and intake of any other medications. Haematology consultation and detailed autoimmune workup to rule out other possible aetiologies (hepatosplenomegaly, autoimmune antinuclear antibodies and antineutrophil cytoplasmic antibodies) were found to be negative.
Following this, a possibility of Olanzapine induced leucopaenia and thrombocytopaenia was considered and the drug was stopped. The patient was admitted for inpatient serial monitoring of haematological parameters and after stopping of Olanzapine, serial monitoring revealed an increase in total leucocyte count $(8900 / \mathrm{cumm})$ and total platelet count back to normal range (156 000/cumm) within a week. Later on, he was started on aripiprazole 2.5 $\mathrm{mg}$ with a very slow hiking of dosage $(2.5 \mathrm{mg} /$ fortnightly $)$ along with monitoring of haematological parameters and psychopathology. At $10 \mathrm{mg}$ of aripiprazole after a period of 30 days, the patient showed significant improvement in mood and psychotic symptoms by around $75 \%$ and his haematological parameters continued to remain stable over the next 4-month follow-up period. The prognosis of the patient was good and there was no relapse of any haematological abnormalities.

\section{DISCUSSION}

In the index elderly subject, olanzapine-associated leucopaenia and thrombocytopaenia were detected just after 6 weeks of starting Olanzapine at a dosage of $15 \mathrm{mg} /$ day. After ruling out all possible causes of these haematological abnormalities, olanzapine was considered to have induced these adverse effects. Leucopaenia and thrombocytopaenia have been rarely reported with olanzapine and the exact incidence rate is currently unavailable. In the literature search, seven published case reports on olanzapine-induced blood dyscrasias have been reported with elderly subjects (details mentioned in table 1 ).

Table 1 Olanzapine-induced blood dyscrasias in the elderly

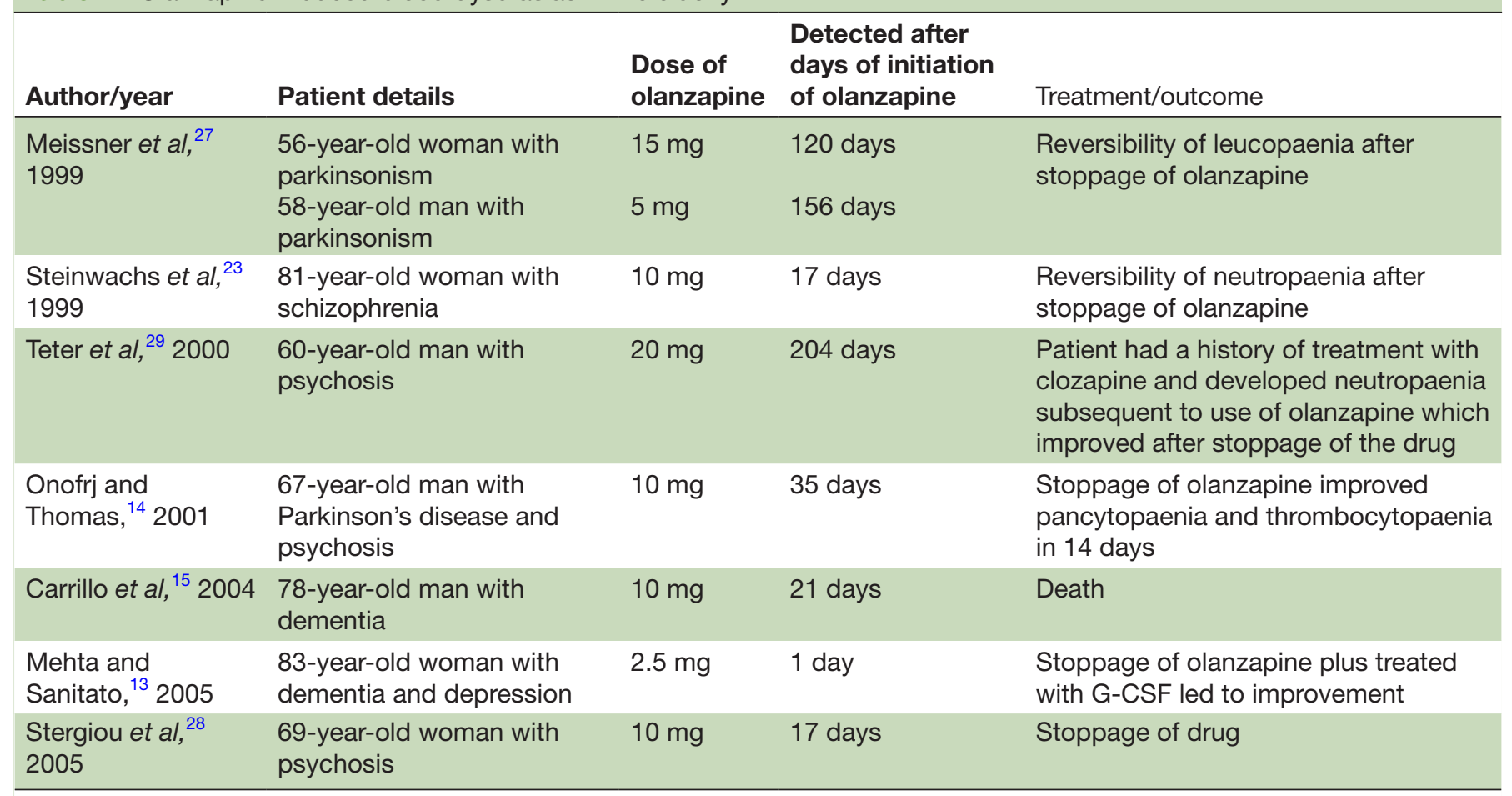

G-CSF, granulocyte colony stimulating factor. 
Pancytopaenia and neutropaenia were also reported with thrombocytopaenia in two of these case reports with elderly subjects. Rechallenge with the same drug was not possible due to ethical reasons.

It was also seen that olanzapine-induced haematological abnormalities can be seen at any time of treatment duration ranging from the first day ${ }^{13}$ to 204 days. ${ }^{29}$ The index case developed leucopaenia and neutropaenia after around 42 days ( 6 weeks) of starting of olanzapine. Of the seven case reports, while there was reported fatality in only in one case ${ }^{15}$, the others improved with stoppage of olanzapine (though one required granulocyte colony stimulating factor (G-CSF) additionally ${ }^{13}$ ). Similarly, stoppage of olanzapine led to improvement in haematological parameters within a week, which further ascertains that olanzapine was the definite agent for inducing leucopaenia and thrombocytopaenia in the index case. The Naranjo probability score ${ }^{30}$ was 9 indicating a definite association of leucopaenia and thrombocytopaenia with olanzapine in the index case.

Though the exact mechanism of action of olanzapine induced neutropaenia and leucopaenia is not known, considering it's chemical structure and pharmacological receptor profile are quite similar to clozapine, those mechanisms proposed for clozapine induced haematological abnormalities can be postulated for olanzapine too. Some of these proposed mechanisms are: (1) olanzapine can modulate levels of the G-CSF and can cause subsequent transient granulocytopaenia like clozapine ${ }^{31}$ and (2) possibly olanzapine use can also lead to formation of nitrenium cations catalysed by Flavin containing monoxenage-3 system of leucocytes like clozapine. ${ }^{32}$ However, both of these hypotheses are not yet proven.

It has been suggested to screen patients as high and low risk for developing olanzapine-induced haematological abnormalities (ie, high risk includes previous history of haematological diseases, family history of blood dyscarcias and any previous history of drug-induced granulocytopaenia) ${ }^{26}$ We further suggest that being an elder be included under high-risk screening for olanzapine-induced haematological abnormalities and a thorough meticulous complete blood count once a month within the first 3 months ${ }^{33}$ be carried out so as to detect any haematological abnormality at the earliest time possible.

The index case adds to the extremely limited literature on olanzapine-induced leucopaenia and thrombocytopaenia in elderly subjects and suggests that whenever an elderly patient receiving olanzapine has objective evidence of any blood dyscrasias, olanzapine must be suspected and stoppage should be considered as early as possible to avoid deleterious results.

Acknowledgements We acknowledge the patient and his family members for providing consent for reporting this case study.

Contributors All the authors were involved in the management of the patient. YKM has drafted the initial manuscript. SS and AA critically evaluated the existing literature and have drafted the final manuscript. All the authors have equal contribution in the preparation of the manuscript.
Funding The authors have not declared a specific grant for this research from any funding agency in the public, commercial or not-for-profit sectors.

Competing interests None declared.

Patient consent Obtained.

Provenance and peer review Not comissioned; externally peer reviewed.

Open access This is an Open Access article distributed in accordance with the Creative Commons Attribution Non Commercial (CC BY-NC 4.0) license, which permits others to distribute, remix, adapt, build upon this work non-commercially, and license their derivative works on different terms, provided the original work is properly cited and the use is non-commercial. See: http://creativecommons.org/ licenses/by-nc/4.0

\section{REFERENCES}

1 Abanmy NO, Al-Jaloud A, Al-Jabr A. Clozapine-induced blood dyscrasias in saudi arab patients. Int J Clin Pharm 2014;36:815-20.

2 Kate N, Grover S, Aggarwal M, et al. Clozapine associated thrombocytopenia. J Pharmacol Pharmacother 2013;4:149-51.

3 Lambertenghi Deliliers G. Blood dyscrasias in clozapine-treated patients in Italy. Haematologica 2000;85:233-7.

4 Semba J, Okui S. Risperidone-induced thrombocytopenia: a case report. Gen Hosp Psychiatry 2009;31:97-8.

5 Dernovsek Z, Tavcar R. Risperidone-induced leucopenia and neutropenia. Br J Psychiatry 1997;171:393-4.

6 López Altimiras FX, Muñoz Rodríguez FJ, Escoté Llobet S. Leukopenia associated to the use of risperidone: a case report and review of the literature. Rev Clin Esp 2006;206:162-3.

7 Manfredi G, Solfanelli A, Dimitri G, et al. Risperidone-induced leukopenia: a case report and brief review of literature. Gen Hosp Psychiatry 2013;35:102.e3-102.e6.

8 Uzun S, Kozumplik O, Jakovljević M, et al. Leukopenia during therapy with risperidone long-acting injectable: two case reports. $J$ Clin Psychopharmacol 2008;28:713-4.

9 Cowan C, Oakley C. Leukopenia and neutropenia induced by quetiapine. Prog Neuropsychopharmacol Biol Psychiatry 2007;31:292-4.

10 Hung WC, Hsieh MH. Neutropenia associated with the comedication of quetiapine and valproate in 2 elderly patients. $J$ Clin Psychopharmacol 2012;32:416-7.

11 Park HJ, Kim JY. Incidence of neutropenia with valproate and quetiapine combination treatment in subjects with acquired brain injuries. Arch Phys Med Rehabil 2016;97:183-8.

12 Rahman A, Mican LM, Fischer C, et al. Evaluating the incidence of leukopenia and neutropenia with valproate, quetiapine, or the combination in children and adolescents. Ann Pharmacother 2009;43:822-30.

13 Mehta A, Sanitato J. A case of neutropenia and thrombocytopenia shortly after initiaing olanzapine. Psychiatry 2005;2:18-19.

14 Onofrj M, Thomas A. One further case of pancytopenia induced by olanzapine in a Parkinson's disease patient. Eur Neurol 2001;45:56-7.

15 Carrillo JA, González JA, Gervasini G, et al. Thrombocytopenia and fatality associated with olanzapine. Eur J Clin Pharmacol 2004;60:295-6.

16 Bogunovic O, Viswanathan R. Thrombocytopenia possibly associated with olanzapine and subsequently with benztropine mesylate. Psychosomatics 2000;41:277-8.

17 Buchman N, Strous RD, Ulman AM, et al. Olanzapine-induced leukopenia with human leukocyte antigen profiling. Int Clin Psychopharmacol 2001;16:55-7.

18 Cordes J, Streit M, Loeffler S, et al. Reversible neutropenia during treatment with olanzapine: three case reports. World $\mathrm{J}$ Biol Psychiatry 2004;5:230-4.

19 Grover S, Hegde A, Agarwal M. Olanzapine-associated leukopenia and thrombocytopenia managed with lithium in a patient who developed leukopenia with clozapine in the past: a case report. Prim Care Companion CNS Disord 2012;14.

20 Konakanchi R, Grace JJ, Szarowicz R, et al. Olanzapine prolongation of granulocytopenia after clozapine discontinuation. J Clin Psychopharmacol 2000;20:703-4.

21 Mathias S, Schaaf LW, Sonntag A. Eosinophilia associated with olanzapine. J Clin Psychiatry 2002;63:246-7.

22 Sahoo S, Singla H, Spoorty M, et al. Thrombocytopenia associated with olanzapine: a case report and review of literature. Indian $J$ Psychiatry 2016;58:339-41. 
23 Steinwachs A, Grohmann R, Pedrosa F, et al. Two cases of olanzapine-induced reversible neutropenia. Pharmacopsychiatry 1999;32:154-6.

24 Thangadurai P, Jyothi KS, Gopalakrishnan R, et al. Reversible neutropenia with olanzapine following clozapine-induced neutropenia. Am J Psychiatry 2006;163:1298.

25 Stip E, Langlois R, Thuot $\mathrm{C}$, et al. Fatal agranulocytosis: the use of olanzapine in a patient with schizophrenia and myelodysplasia. Prog Neuropsychopharmacol Biol Psychiatry 2007;31:297-300.

26 Alageel A, Gaffas E. Hematological safety of olanzapine. European Psychiatry 2016;33:S225.

27 Meissner W, Schmidt T, Kupsch A, et al. Reversible leucopenia related to olanzapine. Mov Disord 1999;14:872-3.

28 Stergiou V, Bozikas VP, Garyfallos G, et al. Olanzapine-induced leucopenia and neutropenia. Prog Neuropsychopharmacol Biol Psychiatry 2005;29:992-4.
29 Teter CJ, Early JJ, Frachtling RJ. Olanzapine-induced neutropenia in patients with history of clozapine treatment: two case reports from a state psychiatric institution. J Clin Psychiatry 2000;61:872-3.

30 Naranjo CA, Busto U, Sellers EM, et al. A method for estimating the probability of adverse drug reactions. Clin Pharmacol Ther 1981;30:239-45.

31 Schuld A, Kraus T, Hinze-Selch D, et al. Granulocyte colonystimulating factor plasma levels during clozapine- and olanzapineinduced granulocytopenia. Acta Psychiatr Scand 2000;102:153-5.

32 Sikora A, Adamus J, Marcinek A. Disproportionation of clozapine radical: a link between one-electron oxidation of clozapine and formation of its nitrenium cation. Chem Res Toxicol 2007;20:1093-8.

33 Freedman JL, Ryan CA, Coffey BJ. Olanzapine-induced agranulocytosis in an adolescent male with psychosis. J Child Adolesc Psychopharmacol 2011;21:185-9.

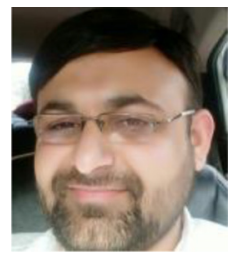

Yogender Kumar Malik completed MBBS program from Mullana medical college, Kurukshetra University, Haryana in 2014, and obtained an MD degree in psychiatry from PGIMER, Chandigarh, India in 2017. He has been working at the department of psychiatry in PGIMER, Chandigarh, India since 2015. His research interests include psychopharmacology and epilepsy.

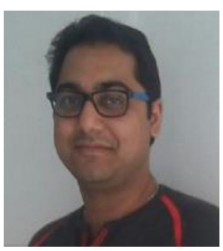

Swapnajeet Sahoo obtained his bachelor's degree from VSS Medical College, Burla, Odisha, India in 2011 and his MD in Psychiatry from the prestigious Post Graduate Institute of Medical Education and Research, Chandigarh, India in 2015. He is currently working as a senior resident in the Department of Psychiatry, Post Graduate Institute of Medical Education and Research, Chandigarh, India. His main research interests include psychopharmacology, psychotherapy, cognitive neurosciences and Schizophrenia. 